\title{
PERFORMANCE EVALUATION OF MEMORY BASED CLASSIFIERS WITH CORRELATION BASED FEATURE SELECTION SUBSET EVALUATOR FOR SMART HEART DISEASE PREDICTION
}

\author{
Lakshmi Devasena. $\mathrm{C}^{\mathbf{1}}$

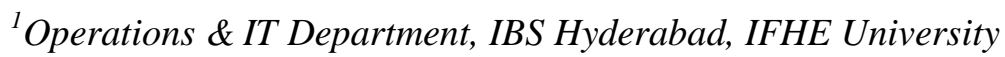

\begin{abstract}
Healthcare industries collect voluminous clinical data which are not able to process manually. Advancements in Technology played a vital role in storing and processing such huge collection of clinical data. Medical decision support systems are intended to support doctors in their diagnosis. This provides effort to widen knowledge and understanding of frequent specialists and facilitates the diagnosis process, using patients' data from clinical databases. Identification of heart disease is a momentous and difficult task in medicine. It is crucial to find the best fit classification algorithm that has greater accuracy on classification in heart disease prediction. This research work compares the competence of Memory based classifiers for prediction of heart diseases by taking several measures using open access machine learning tool.
\end{abstract}

Keywords—Heart Disease Prediction; Memory based Classifiers; Performance Comparison

\section{INTRODUCTION}

Medical data mining is an exploring field of data mining, where different data mining and classification techniques are used to predict the diseases based on the existing clinical data. Health care industries store huge amount of data of patients which can be used for this purpose. Even the serious diseases like 'Heart Attack' have some common symptoms which are used to predict the disease. Based on the past existing data if a classification model could be prepared, and then it is easy for the physician to predict the disease using basic clinical data and initiates the treatment without waiting for other medical modality results. Medical decision support systems use Medical data mining approach to support diagnosing process. Mainly classification algorithms play an important role for this purpose. The accuracy of the classification will be based on the accurate and enough training data available. Varieties of classification algorithms exist to predict the unknown data and Computer Science and Engineering Researchers have an opportunity to study the algorithms and suggest the best performing algorithm. This research work experiments and compares the performance of Memory based classifiers in predicting Heart Disease.

\section{LITERATURE REVIEW}

There are numerous works coming up for better heart disease prediction. Researchers showing interest in this area to find the better algorithms which gives superior accuracy and analyzing various measures to study the performance of different algorithms. The algorithms like neuro-fuzzy integrated approach, combined technique of Maximal Frequent Item set Algorithm+ C4.5+ K-means algorithm, Artificial Neural Network with Feature Subset Selection and Principal component Analysis are analyzed for heart disease prediction in [1], [2], [3] and [11]. SPAM algorithm with
Nearest Neighbor Classifier, Genetic Algorithm for variety of Optimal Reduced Set of Attributes and Naive Bayes with Decision Tree classifier, C4.5 and C5.0 decision tree algorithm with Rule reduction are compared and analyzed for heart disease prediction in [4], [5] and [6]. Cluster based Association Rule Mining using sequence number, SMO, Logistic Function and Multilayer Perceptron, K- Nearest Neighbor Algorithm are analyzed and compared for heart disease prediction in [7] and [8], [10] and [12]. Review reports on Heart Disease data set prediction by various researchers are summarized in [9], [13], [16] and [27]. The possibilities, advantages and usage of Data Mining in Health care to predict diseases are elaborated in [14] and [22]. Adaptive Neuro-Fuzzy Inference system with Hybrid Learning algorithm, Artificial Neural Network with Multilayer Perceptron using Back Propagation algorithm, Classification and Regression Tree (CART) Model algorithms are analyzed for Heart Disease prediction is described in [15], [17], [18] and [30] and these algorithms compared the accuracy of classifiers with other classifiers in the existing literature. Cascaded Neural Network Classifier and Support vector machine algorithm, Naive Bayes, Neural Networks and Decision tree Combination, CART, ID3 and Decision Tree classifier combination are analyzed and compared for heart disease prediction in [19], [20], [22], [23] and [28]. Equal Frequency Discretization Gain Ratio Decision Tree, J48 Decision Tree classifier and Bagging algorithm, Neural Network, Support Vector Machine and KMeans Clustering combination are analyzed and compared for heart disease prediction in [21] and [24]. Web-based application entitled Decision Support in Heart Disease Prediction System is offered in [25] using data mining technique. Naive Bayes, Decision Table and J48 algorithm combination for heart disease prediction is suggested in [26]. Naive Bayes, Decision Tree with K-Means and Weighted 
Associative Classifier with Apriori Algorithm combination are analyzed and compared for heart disease prediction in [29]. Naive Bayes classifier and Support Vector machine are separately assessed and compared in [31] for heart disease prediction. Naive Bayes with Jelinek-mercer smoothing combination for heart disease prediction is explained in [32]. Random Forest and J48 Classifiers are separately evaluated and compared for heart disease prediction in [33]. LMT and FT Classifiers are separately analyzed and compared for heart disease prediction in [34]. Memory Based Classifiers (without any attribute selection method) are separately analyzed and compared for heart disease prediction in [35] and [38]. ZeroR, RIDOR and PART Classifiers are separately tested and compared for heart disease prediction in [36]. Functional Tree Classifier and Random Forest Classifier are separately analyzed and compared for heart disease prediction in [37]. Memory based classifiers is used in many classification problems, its usage is explained for credit risk prediction in [39-43]. This work investigates the performance comparison of Memory based classifiers separately with CFS Attribute evaluation for prediction Heart Disease.

\section{DATASET USED}

This work uses the Statlog Heart Disease dataset from UCI machine learning repository [44] with a sum of 270 instances with 13 medical attributes. This dataset contains instances of 120 patients with heart disease and 150 patients without heart disease. The class value " 1 " is used to indicate the absence of heart disease and class value " 2 " is used to indicate the presence of heart disease. The attributes are as: age, sex, chest, trestbps, chol, fasting blood sugar, restecg, thalach, exang, oldpeak, slope, ca, and thal.

\section{METHODOLOGY USED}

In machine learning, memory-based learning is a family of learning algorithms that compare new problem instances with instances seen in training, which have been stored in memory. Memory based learning is a kind of lazy learning. It is called Memory based because it constructs postulates directly from the training instances. It has different advantages like, Learning complex target Functions easily, Very fast training, No information loss, and the ability to adapt its model to previously unseen data. This work compares the following memory based classification algorithms.

CFS (Correlation based Feature Selection) Subset Evaluator or Attribute Selector, assesses the worth of a subset of attributes by considering the individual foretelling ability of each attribute along with the degree of severance between them.

\subsection{IBk Classifier}

IBK is an employment of the k-nearest-neighbor classifier. Every instance in the dataset is deliberated as a point in multi-dimensional space and classification is done based on the class value of ' $k$ ' nearest neighbors. The value of ' $k$ ' decides how many neighbors can be taken for consideration to elect how to classify a new instance.

For example, for the 'heart disease' data, IBK would consider the 7 dimensional spaces for the 7 attributes. A new instance would be classified to the class of its closest neighbor using Euclidean distance measurement. If ' 8 ' is used as the value of ' $k$ ', then eight closest neighbors will be considered. The class of the new instance is considered to be the class of the majority of the instances. If ' 8 ' is used as the value of $k$ and 5 or 6 of the closest neighbors are of class value ' 1 ', then the class value of the test instance would be assigned as ' 1 '. The time taken to classify a test instance with nearest-neighbor classifier rises linearly with the number of training cases".

\subsection{K Star Classifier}

$\mathrm{K}$ Star is a memory-based classifier that is the class of a new instance is based upon the class of training instances similar to it, as determined by some similarity measure. The use of entropy as a similarity measure has numerous benefits in $\mathrm{K}$ Star. Amongst other classifiers, it provides a reliable approach to handling of real valued attributes, symbolic attributes and missing values [45].

\subsection{Locally Weighted Learning Classifier}

Locally Weighted Learning (LWL) is a learning model belongs to the category of memory based classifiers. LWL model with Decision Stump in combination is a classifier. Decision Stump habitually used in combination with a boosting algorithm. Boosting is most significant recent development in classification methodology. Boosting is done by sequentially applying a classification algorithm to reweighted versions of the training data, and then obtaining a weighted maximum vote of the sequence of classifiers thus created. For numerous classification algorithms, this simple strategy results in dramatic performance improvement. This apparently inexplicable phenomenon can be understood in terms of well known statistical principles, namely maximum likelihood and additive modeling. For the twoclass problem, boosting can be observed as an approximation to additive modeling [46].

\section{PERFORMANCE MEASURES USED}

Various measures are used to gauge the performance of Memory based classifiers.

\subsection{Classification Accuracy}

Classification accuracy is computed as correctly classified instances by number of total instances multiplied by 100 .

\subsection{Cohen's Kappa}

It is a statistics which measures the inter-rate settlement between the classes. In this case, it is the inter-rate agreement between Presence of heart disease and Absence of Heart disease. 


\subsection{Mean Absolute Error}

Mean absolute error is the average of the variance between predicted and actual value in all instances. It is a good measure to measure the performance.

\subsection{Root Mean Square Error}

Root mean squared error is used to scale variations between values actually professed and the values predicted by the model. It is defined by taking the square root of the mean square error.

\section{RESULTS AND DISCUSSION}

The performance of Memory based Classifiers with CSF attribute evaluator separately experimented for heart disease prediction using open source machine learning tool. The performance is tested out using the Training set as well as using various cross validation methods. The results are arrived by considering only resulting attributes from CSFAE method namely, chest, resting electrocardiographic results, exercise induced angina, maximum heart rate achieved, old peak, number of major vessels and thal of the dataset.

\subsection{Performance of IBk Classifier with CFS Subset}

\section{Evaluator}

The assessment summary of IBk Classifier done with entire training set and various cross validation methods is depicted in Table I. IBk Classifier gives $100 \%$ accuracy for the training data set. Various cross validation methods (5 Fold, 10 Fold, 15 Fold, etc.) are used to check its actual performance of IBk. On an average, it gives around $77.78 \%$ of accuracy which is $3 \%$ more than the accuracy $(74.75 \%$ of accuracy) got by only using IBk classifier without ant attribute selection method [35] for heart disease prediction.

IBk Classifier with CFSAE Evaluation Summary

\begin{tabular}{|c|c|c|c|c|c|c|}
\hline $\begin{array}{l}\text { Test } \\
\text { Mod } \\
\text { e }\end{array}$ & $\begin{array}{l}\text { Correct } \\
\text { ly } \\
\text { Classifi } \\
\text { ed } \\
\text { Instanc } \\
\text { es }\end{array}$ & $\begin{array}{l}\text { Accurac } \\
\mathbf{y}\end{array}$ & $\begin{array}{l}\text { Kapp } \\
\text { a }\end{array}$ & $\begin{array}{l}\text { Mea } \\
\text { n } \\
\text { Abs } \\
\text { olut } \\
\text { e } \\
\text { Erro } \\
\text { r }\end{array}$ & $\begin{array}{l}\text { Root } \\
\text { Mea } \\
\text { n } \\
\text { Squ } \\
\text { ared } \\
\text { Erro } \\
\text { r }\end{array}$ & $\begin{array}{l}\text { Time } \\
\text { Take } \\
\text { n to } \\
\text { Build } \\
\text { Mode } \\
\text { l } \\
\text { (Sec) }\end{array}$ \\
\hline $\begin{array}{l}\text { Trai } \\
\text { ning } \\
\text { Set }\end{array}$ & 270 & $100 \%$ & 1 & 0 & 0 & 0 \\
\hline $\begin{array}{l}5 \\
\text { FCV }\end{array}$ & 207 & $\begin{array}{l}76.6667 \\
\%\end{array}$ & $\begin{array}{l}0.526 \\
3\end{array}$ & $\begin{array}{l}0.23 \\
33\end{array}$ & $\begin{array}{l}0.48 \\
3\end{array}$ & 0 \\
\hline $\begin{array}{l}10 \mathrm{~F} \\
\mathrm{CV}\end{array}$ & 210 & $\begin{array}{l}77.7778 \\
\%\end{array}$ & 0.547 & $\begin{array}{l}0.22 \\
22\end{array}$ & $\begin{array}{l}0.47 \\
14\end{array}$ & 0 \\
\hline $\begin{array}{l}15 \\
\text { FCV }\end{array}$ & 213 & $\begin{array}{l}78.8889 \\
\%\end{array}$ & 0.57 & $\begin{array}{l}0.21 \\
11\end{array}$ & $\begin{array}{l}0.45 \\
95\end{array}$ & 0 \\
\hline $\begin{array}{l}20 \\
\text { FCV }\end{array}$ & 210 & $\begin{array}{l}77.7778 \\
\%\end{array}$ & 0.547 & $\begin{array}{l}0.22 \\
22\end{array}$ & $\begin{array}{l}0.47 \\
14\end{array}$ & 0 \\
\hline $\begin{array}{l}50 \\
\text { FCV }\end{array}$ & 210 & $\begin{array}{l}77.7778 \\
\%\end{array}$ & $\begin{array}{l}0.546 \\
2\end{array}$ & $\begin{array}{l}0.22 \\
22 \\
\end{array}$ & $\begin{array}{l}0.47 \\
14 \\
\end{array}$ & 0 \\
\hline
\end{tabular}

\subsection{Performance of $\mathrm{K}$ Star Classifier with CFS}

\section{Subset Evaluator}

The overall assessment summary of K Star Classifier done with entire training set and various cross validation methods is depicted in Table II. K Star Classifier gives $99.6296 \%$ accuracy for the training data set. Various cross validation methods (5 Fold, 10 Fold, 15 Fold, etc.) are used to check its actual performance of $\mathrm{K}$ Star. On an average, it gives around $79.18 \%$ of accuracy which is $3.28 \%$ more than the accuracy (75.90\% of accuracy) got by only using K Star classifier without ant attribute selection method [35] for heart disease prediction.

K Star Classifier with CFSAE Evaluation Summary

\begin{tabular}{|c|c|c|c|c|c|c|}
\hline $\begin{array}{l}\text { Test } \\
\text { Mode }\end{array}$ & $\begin{array}{l}\text { Correct } \\
\text { ly } \\
\text { Classifi } \\
\text { ed } \\
\text { Instanc } \\
\text { es }\end{array}$ & $\begin{array}{l}\text { Accura } \\
\text { cy }\end{array}$ & $\begin{array}{l}\text { Kap } \\
\text { pa }\end{array}$ & $\begin{array}{l}\text { Mea } \\
\text { n } \\
\text { Abs } \\
\text { olut } \\
\text { e } \\
\text { Erro } \\
\text { r }\end{array}$ & $\begin{array}{l}\text { Root } \\
\text { Mea } \\
\text { n } \\
\text { Squ } \\
\text { ared } \\
\text { Erro } \\
\text { r }\end{array}$ & $\begin{array}{l}\text { Time } \\
\text { Take } \\
\text { n to } \\
\text { Build } \\
\text { Mode } \\
\text { l } \\
\text { (Sec) }\end{array}$ \\
\hline $\begin{array}{l}\text { Trainin } \\
\text { g Set }\end{array}$ & 269 & $\begin{array}{l}99.6296 \\
\%\end{array}$ & $\begin{array}{l}0.99 \\
25\end{array}$ & $\begin{array}{l}0.03 \\
34\end{array}$ & $\begin{array}{l}0.08 \\
04\end{array}$ & 0 \\
\hline $5 \mathrm{FCV}$ & 212 & $\begin{array}{l}78.5185 \\
\%\end{array}$ & $\begin{array}{l}0.55 \\
84\end{array}$ & $\begin{array}{l}0.24 \\
52\end{array}$ & $\begin{array}{l}0.40 \\
43\end{array}$ & 0 \\
\hline $\begin{array}{l}10 \\
\text { FCV }\end{array}$ & 211 & $\begin{array}{l}78.1481 \\
\%\end{array}$ & $\begin{array}{l}0.55 \\
11\end{array}$ & $\begin{array}{l}0.24 \\
45\end{array}$ & $\begin{array}{l}0.40 \\
1\end{array}$ & 0 \\
\hline $\begin{array}{l}15 \\
\text { FCV }\end{array}$ & 216 & $80 \%$ & $\begin{array}{l}0.58 \\
81\end{array}$ & $\begin{array}{l}0.24 \\
26\end{array}$ & $\begin{array}{l}0.39 \\
61\end{array}$ & 0 \\
\hline $\begin{array}{l}20 \\
\text { FCV }\end{array}$ & 214 & $\begin{array}{l}79.2593 \\
\%\end{array}$ & $\begin{array}{l}0.57 \\
29\end{array}$ & $\begin{array}{l}0.24 \\
26\end{array}$ & $\begin{array}{l}0.39 \\
67\end{array}$ & 0.05 \\
\hline $\begin{array}{l}50 \\
\text { FCV }\end{array}$ & 216 & $80 \%$ & $\begin{array}{l}0.58 \\
74\end{array}$ & $\begin{array}{l}0.24 \\
32\end{array}$ & $\begin{array}{l}0.39 \\
64\end{array}$ & 0 \\
\hline
\end{tabular}

\subsection{Performance of LWL Classifier with CFS}

\section{Subset Evaluator}

The overall assessment summary of LWL Classifier done with entire training set and various cross validation methods is depicted in Table III. LWL Classifier gives $80.7407 \%$ accuracy for the training data set. Different cross validation methods (5 Fold, 10 Fold, 15 Fold, etc.) are used to check its actual performance of LWL. On an average, it gives around $69.037 \%$ of accuracy which is $2 \%$ less than the accuracy (71.10\% of accuracy) got by only using LWL classifier without ant attribute selection method [35] for heart disease prediction. 
LWL Classifier with CFSAE Evaluation Summary

\begin{tabular}{|l|l|l|l|l|l|l|}
\hline $\begin{array}{l}\text { Test } \\
\text { Mod } \\
\text { e }\end{array}$ & $\begin{array}{l}\text { Correct } \\
\text { Classifi } \\
\text { ed } \\
\text { Instanc } \\
\text { es }\end{array}$ & $\begin{array}{l}\text { Accura } \\
\text { cy }\end{array}$ & Kappa & $\begin{array}{l}\text { Mea } \\
\text { n } \\
\text { Abs } \\
\text { olut } \\
\text { e } \\
\text { Erro } \\
\text { r }\end{array}$ & $\begin{array}{l}\text { Root } \\
\text { Mea } \\
\text { Squ } \\
\text { ared } \\
\text { Erro } \\
\text { r }\end{array}$ & $\begin{array}{l}\text { Time } \\
\text { Take } \\
\text { n to } \\
\text { Build } \\
\text { Mode } \\
\text { l } \\
\text { (Sec) }\end{array}$ \\
\hline $\begin{array}{l}\text { Trai } \\
\text { ning } \\
\text { Set }\end{array}$ & 218 & $\begin{array}{l}80.7407 \\
\%\end{array}$ & 0.6139 & $\begin{array}{l}0.30 \\
73\end{array}$ & 0.37 & 0 \\
\hline 5 & 192 & $\begin{array}{l}71.1111 \\
\text { FCV }\end{array}$ & 0.4227 & $\begin{array}{l}0.35 \\
11\end{array}$ & 0.43 & 01 \\
\hline $\begin{array}{l}10 \\
\text { FCV }\end{array}$ & 189 & $70 \%$ & 0.399 & $\begin{array}{l}0.35 \\
8\end{array}$ & $\begin{array}{l}0.43 \\
44\end{array}$ \\
\hline $\begin{array}{l}15 \\
\text { FCV }\end{array}$ & 182 & $\begin{array}{l}67.4074 \\
\%\end{array}$ & 0.3455 & $\begin{array}{l}0.36 \\
97\end{array}$ & 0.44 \\
\hline $\begin{array}{l}20 \\
\text { FCV }\end{array}$ & 184 & $\begin{array}{l}68.1481 \\
\%\end{array}$ & 0.3614 & $\begin{array}{l}0.36 \\
76\end{array}$ & 0.44 & 0 \\
\hline $\begin{array}{l}50 \\
\text { FCV }\end{array}$ & 185 & $\begin{array}{l}68.5185 \\
\%\end{array}$ & 0.3683 & $\begin{array}{l}0.36 \\
64\end{array}$ & $\begin{array}{l}0.44 \\
22\end{array}$ \\
\hline
\end{tabular}

\subsection{Comparison of Memory based Classifiers}

The comparison of performance of Memory based Classifiers with and without CFS attribute evaluator is depicted in Fig 1, Fig 2, and Fig 3 separately for IBk, K Star and LWL classifiers based on accuracy. Comparison of overall performance of all classifiers with CFS attribute evaluator is depicted in Fig 4 and Fig 5 in terms of Classification Accuracy and Correctly Classified Instances. The complete evaluation is done based on classification accuracy, Kappa statistics, MAE and RMSE values found using Training Set result and Cross Validation Techniques. Consequently, it is perceived that K Star classifier performs better than other classifiers followed by IBk and LWL Classifier.

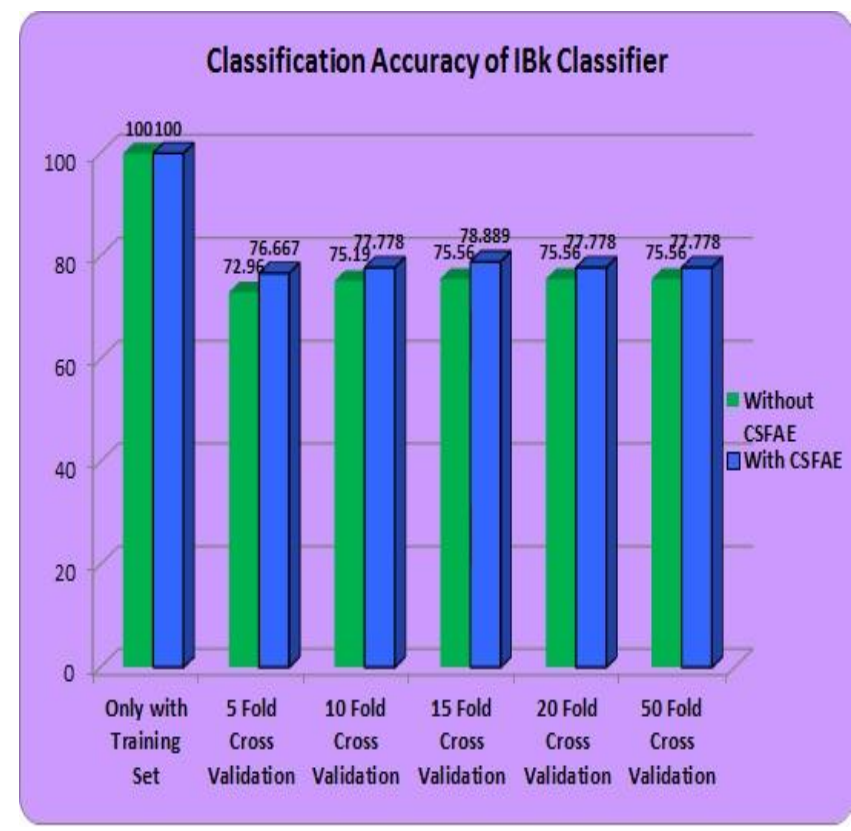

Classification Accuracy Comparison of IBK Classifier with and without CFS Attribute Selection

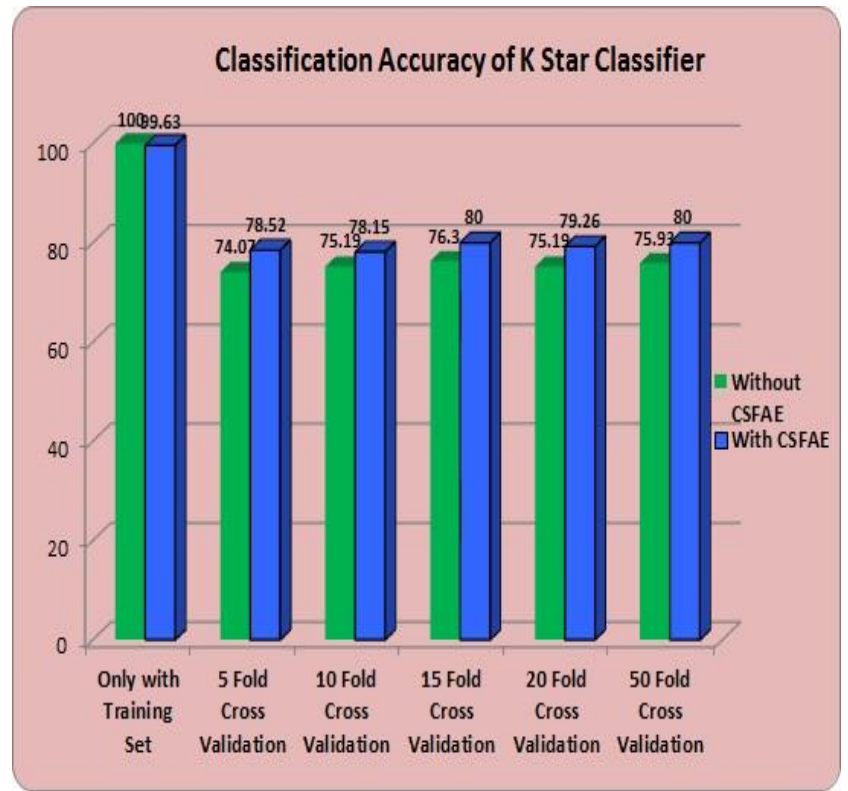

Classification Accuracy Comparison of K Star Classifier with and without CFS Attribute Selection

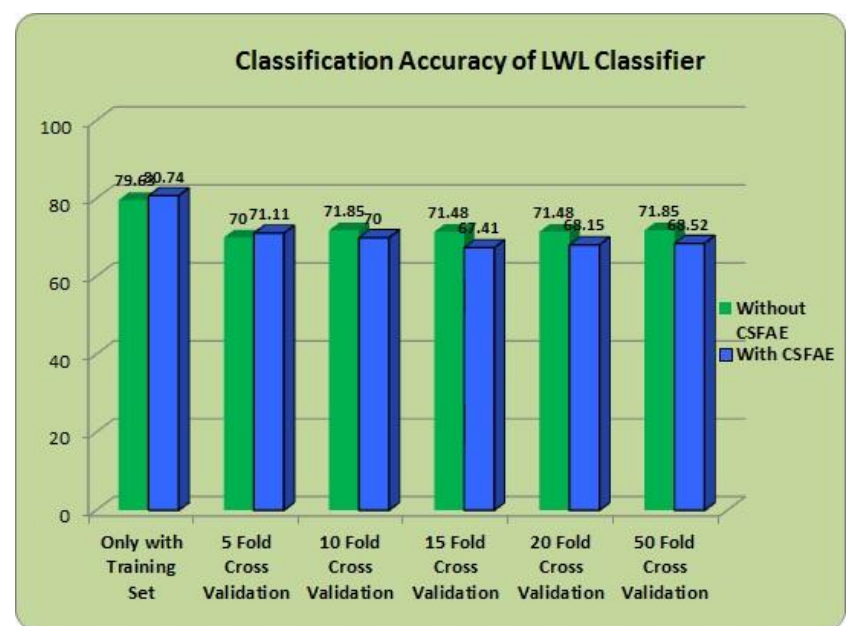

Classification Accuracy Comparison of LWL Classifier with and without CFS Attribute Selection

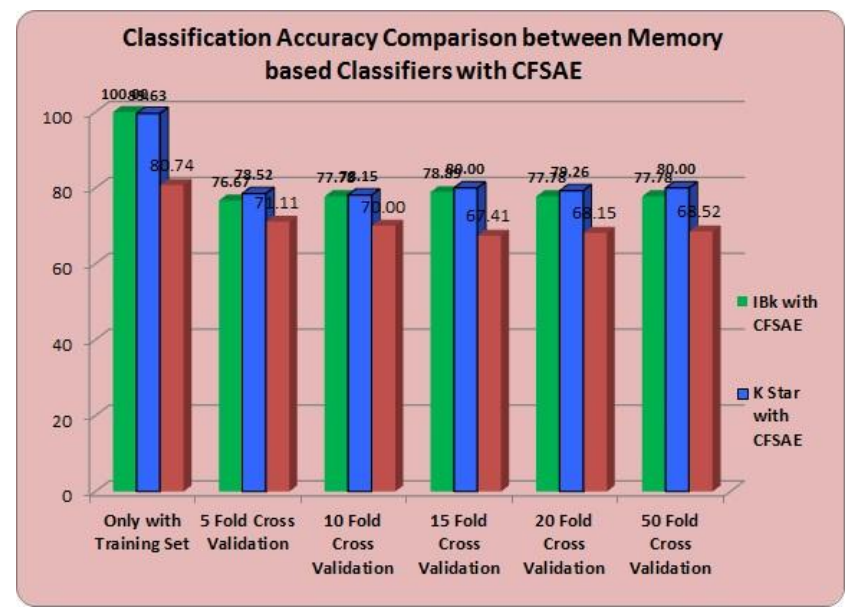

Classification Accuracy Comparison between Memory based Classifiers with CFS Attribute Selection 


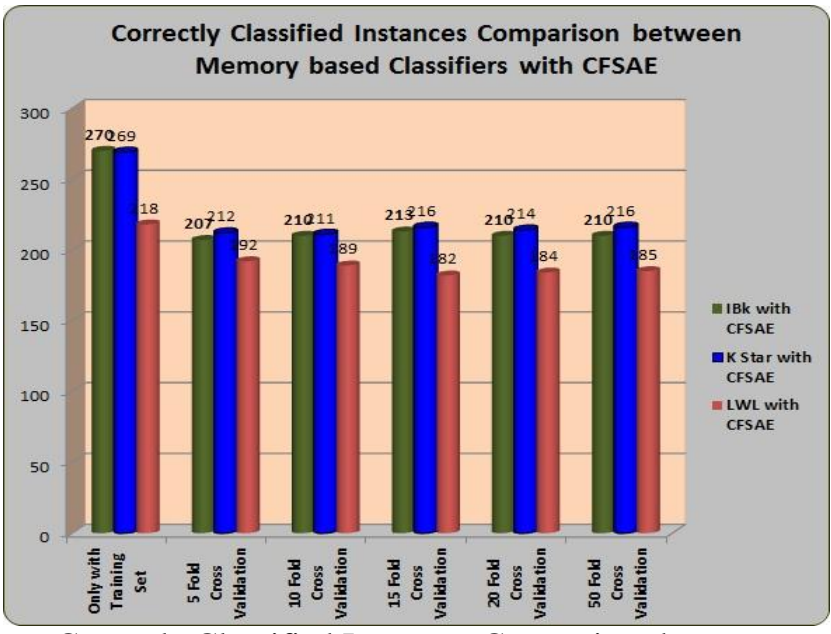

Correctly Classified Instances Comparison between Memory based Classifiers with CFS Attribute Selection

\section{CONCLUSION}

This work investigated the efficiency of Memory based classifiers namely; IBk Classifier, K Star Classifier and LWL Classifier with CFS attribute evaluator for heart disease prediction. Experiment is done using the open source machine learning tool. Also, performance evaluation of the classifiers has been done in view of various scales of performance measure. At last, it is observed that K Star classifier performs better than other classifiers followed by IBk Classifier and by LWL with very lower accuracy for heart disease prediction by taking various measures.

\section{ACKNOWLEDGMENT}

The author expresses her deep gratitude to the Management of IBS Hyderabad, IFHE University for the support and motivation provided for the research work.

\section{REFERENCES}

[1] Ashish Kumar Sen, Shamsher Bahadur Patel, and D. P. Shukla, "Data Mining Technique for Prediction of Coronary Heart Disease Using Neuro-Fuzzy Integrated Approach Two Level", Int. Journal of Engg. and Comp. Science, vol. 2 Issue 9, pp. 26632671, Sept 2013.

[2] V. Manikantan and S. Latha, "Predicting the Analysis of Heart Disease Symptoms Using Medicinal Data Mining Methods", International Journal on Advanced Computer Theory and Engineering, vol. 2, Issue-2, pp. $5-10,2013$.

[3] M. Akhil Jabbar, B.L Deekshatulu, and Priti Chandra, "Classification of Heart Disease using Artificial Neural Network and Feature Subset Selection", Global Journal of Computer Science and Technology Neural \& Artificial Intelligence, vol. 13 Issue 3, 2013.

[4] S. Sandhiya, P. Pavithra, A. Vidhya, S. Jegan and S. Saranya, "Novel Approach for Heart Disease verdict Using Data Mining Technique", International Journal of Modern Engineering Research, pp. 10-14.
[5] Shruti Ratnakar, K. Rajeswari, and Rose Jacob, "Prediction of Heart Disease Using Genetic Algorithm For Selection of Optimal Reduced Set of Attributes", International Journal of Advanced Computational Engineering and Networking, vol.-1, Issue-2, pp. 51 - 55, April-2013.

[6] Mohammad Taha Khan, Shamimul Qamar and Laurent F. Massin, "A Prototype of Cancer/Heart Disease Prediction Model Using Data Mining", International Journal of Applied Engineering Research, vol.7 No.11, 2012.

[7] M.Akhil jabbar, Priti Chandra, and B.L Deekshatulu, "Heart Disease Prediction System using Associative Classification and Genetic Algorithm", International Conference on Emerging Trends in Electrical, Electronics and Communication Technologies, 2012.

[8] MA. Jabbar, Priti Chandra, and B.L. Deekshatulu, "Cluster Based Association Rule Mining for Heart Attack Prediction", Journal of Theoretical and Applied Information Technology, Vol. 32 No.2, pp. 196 - 201, 31st October 2011.

[9] S.Vijayarani and S.Sudha, " A Study of Heart Disease Prediction in Data Mining", International Journal of Computer Science and Information Technology \& Security, Vol. 2, No.5, pp. 1041 1045, October 2012.

[10] S.Vijayarani, and S.Sudha, "Comparative Analysis of Classification Function Techniques for Heart Disease Prediction", International Journal of Innovative Research in Computer and Communication Engineering, Vol. 1, Issue 3, pp. 735 - 741, May 2013.

[11] G.Karthiga, C.Preethi, R.Delshi, and Howsalya Devi, "Heart Disease Analysis System Using Data Mining Techniques", International Journal of Innovative Research in Science, Engineering and Technology, vol. 3, Special Issue 3, pp. 3101 - 3105, March 2014.

[12] Mai Shouman, Tim Turner, and Rob Stocker, "Applying k-Nearest Neighbour in Diagnosing Heart Disease Patients", International Journal of Information and Education Technology, Vol. 2, No. 3, pp. $220-223$, June 2012.

[13] K.Srinivas, G.Raghavendra Rao and A.Govardhan, "Survey on Prediction of Heart Morbidity Using Data Mining Techniques", International Journal of Data Mining \& Knowledge Management Process (IJDKP) Vol.1, No.3, pp.14 - 34, May 2011.

[14] Boris Milovic and Milan Milovic, "Prediction and Decision Making in Health Care using Data Mining,", International Journal of Public Health Science, Vol. 1, No. 2, pp. 69 - 78, December 2012.

[15] Negar Ziasabounchi and ImanAskerzade, "ANFIS Based Classification Model for Heart Disease Prediction", International Journal of Electrical \& Computer Sciences, vol.14, No. 2, pp. 7-12, April 2014.

[16] S.J Gnanasoundhari, G.Visalatchi, and.M.Balamurugan, "A Survey on Heart Disease Prediction System Using Data Mining Techniques", International Journal of Computer Science and 
Mobile Applications, Vol.2 Issue. 2, pp. 72-77, February 2014.

[17] Chaitrali S. Dangare, and Sulabha S. Apte, "A Data Mining Approach for Prediction of Heart Disease using Neural Networks", International Journal of Computer Engineering and Technology, vol. 3, Issue 3, pp. 30-40, October - December 2012.

[18] Mohammad Subhi Al-batah, "Testing the Probability of Heart Disease Using Classification and Regression Tree Model", Annual Research \& Review in Biology, vol. 4, no. 11, pp. 1713-1725, 2014.

[19] R. Chitra and V. Seenivasagam, "Heart Disease Prediction System Using Supervised Learning Classifier", Bonfring International Journal of Software Engineering and Soft Computing, Vol. 3, No. 1, pp. 1 - 7, March 2013.

[20] Vikas Chaurasia, et al, "Early Prediction of Heart Diseases Using Data Mining Techniques", Carib.j.SciTech, vol. 1, pp. 208-217, 2013.

[21] Mai Shouman, Tim Turner, and Rob Stocker, "Using Decision Tree for Diagnosing Heart Disease Patients" Proceedings of the 9-th Australasian Data Mining Conference 2011 (AusDM'11), Ballarat, Australia, pp. $23-29,2011$.

[22] Priti V. Wadal, and S. R. Gupta, "Predictive Data Mining For Medical Diagnosis: An Overview Of Heart Disease Prediction", International Journal of Engineering Research and Applications, pp. 1 -4, April 2014.

[23] Aditya Methaila, Prince Kansal, Himanshu Arya, and Pankaj Kumar, "Early Heart Disease Prediction using Data Mining Techniques", Sundarapandian et al. (Eds) : CCSEIT, DMDB, ICBB, MoWiN, AIAP 2014, pp. 53-59, 2014.

[24] Aqueel Ahmed, and Shaikh Abdul Hannan, "Data Mining Techniques to Find Out Heart Diseases: An Overview", International Journal of Innovative Technology and Exploring Engineering, vol. 1, Issue 4, pp. 18 - 23, September 2012.

[25] D. Raghu. T. Srikanth, and Ch. Raja Jacub, "Probability based Heart Disease Prediction using Data Mining Techniques", IJCST, vol. 2, Issue 4, pp. 66 - 68, Oct - Dec. 2011.

[26] Hari Ganesh S, and Gajenthiran M, "Comparative study of Data Mining Approaches for prediction Heart Diseases", International organization of Scientific Research IOSR Journal of Engineering, vol. 04, Issue 07, pp. 36-39, July. 2014.

[27] Hariganesh S, and Gajenthiran M, "A Survey: Data Mining Approaches for Prediction of Heart Disease", International Journal of Engineering Science Invention, vol. 3 Issue 4, pp. 44-46, April 2014.

[28] K. Thenmozhi, P. Deepika, and M.Meiyappasamy, "Different Data Mining Techniques Involved in Heart Disease Prediction: A Survey", International Journal of Scientific Research, vol. 3, Issue 9, pp. $67-68$, September 2014.

[29] Aswathy Wilson, Jismi Simon, Liya Thomas, and Soniya Joseph, "Data Mining Techniques For Heart Disease Prediction", International Journal of
Advances in Computer Science and Technology, vol. 3, No.2, pp. 113- 116, February 2014.

[30] Manjusha B. Wadhonkar, P. A. Tijare and S. N. Sawalkar, "Classification of Heart Disease Dataset using Multilayer Feed forward back propagation Algorithm", International Journal Application or Innovation in Engineering \& Management, vol. 2, Issue 4, pp. 213 - 220, April 2013.

[31] G. Parthiban and S.K.Srivatsa, "Applying Machine Learning Methods in Diagnosing Heart Disease for Diabetic Patients", International Journal of Applied Information Systems, vol. 3- No.7, pp. 25 - 30, August 2012.

[32] Rupali R.Patil, "Heart Disease Prediction System using Naive Bayes and Jelinek-mercer smoothing", International Journal of Advanced Research in Computer and Communication Engineering, vol. 3, Issue 5, May 2014.

[33] Lakshmi Devasena, C. 2016. Proficiency Comparison of Random Forest and J48 Classifiers for Heart Disease Prediction. International Journal of Computing Academic Research (IJCAR), Volume 5, Number 1 (February 2016), pp.46-55.

[34] Lakshmi Devasena, C. 2015. "Comparative Analysis of LMT and FT Classifiers for Smart Heart Disease Prophecy", International Journal of Core Engineering $\&$ Management (IJCEM), Special issue, ICCEMT2015, (December 2015), pp. 368 - 380.

[35] Lakshmi Devasena, C. 2015. Comparative Analysis of Memory Based Classifiers for Intelligent Heart Disease Prediction. International Journal of Applied Engineering Research (IJAER), Volume 10, Number 81, pp. 109-113.

[36] Lakshmi Devasena, C. 2014. Proficiency Comparison of ZeroR, RIDOR and PART Classifiers for Intelligent Heart Disease Prediction. International Journal of Advances in Computer Science and Technology, Vol.3, No.11, pp. 12-18 (2014) Special Issue.

[37] Lakshmi Devasena C, "Comparative Analysis of Functional Tree Classifier and Random Forest Classifier for Smart Heart Disease Prediction", Proc. of 4th International Conference on Communications, Signal Processing Computing and Information Technologies (ICCSPCIT-2015), December 2015, pp. 6-10, ISBN No. 978-93-83038-27-5.

[38] Lakshmi Devasena, C. 2015. Comparative Analysis of Memory Based Classifiers for Intelligent Heart Disease Prediction. In Proc. of International Conference on Innovations in Computer Science and Information Technology - ICICSIT 2015, ISBN: 978-93-85100-08-6. (Publisher: Paramount Publishing House, Hyderabad, India)

[39] Lakshmi Devasena C, "Classification of Multivariate Data Sets without Missing Values using Memory Based Classifiers - An Effectiveness Evaluation", International Journal of Artificial Intelligence \& Applications (IJAIA), Vol.4, No.1, pp. 129 - 142, January 2013. 
[40] Lakshmi Devasena C, "Classification of Incomplete Multivariate Datasets using Memory Based Classifiers - A Proficiency Evaluation", International Journal of Advanced Trends in Computer Science and Engineering, Vol.2, No.1, pp. 148-153, 2013.

[41] Lakshmi Devasena C, "Adeptness Evaluation of Memory Based Classifiers for Credit Risk Analysis", Proc. of International Conference on Intelligent Computing Applications - ICICA 2014, 6-7, 978-14799-3966-4/14 (IEEE Explore), pp. 143-147, March 2014.

[42] Lakshmi Devasena C, "Adeptness Comparison between Instance Based and K Star Classifiers for Credit Risk Scrutiny", International Journal of Innovative Research in Computer and Communication Engineering, Vol.2, Special Issue 1, March 2014.

[43] Lakshmi Devasena C, "Effectiveness Prediction of Memory Based Classifiers for the Classification of Multivariate Data Set", Sundarapandian et al. (Eds): CoNeCo, WiMo, NLP, CRYPSIS, ICAIT, ICDIP, ITCSE, CS \& IT 07, pp. 413-424, 2012.

[44] UCI Machine Learning Data Repository http://archive.ics.uci.edu/ml/datasets.

[45] John G. Cleary, " $\mathrm{K}^{*}$ : An Instance-based Learner Using an Entropic Distance Measure".

[46] Christopher G. Atkeson, Andrew W. Moore and Stefan Schaal, "Locally Weighted Learning" October 1996.

\section{BIOGRAPHY}

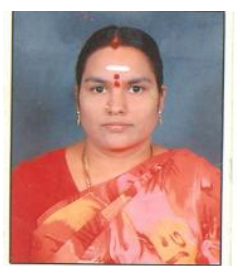

Dr. C. Lakshmi Devasena has 13 years of Teaching and two years of Industrial experience. She has published 56 papers, in that 40 papers are published in International Journals and 16 are published in National Journals and conference proceedings. She has presented 46 papers in various International and National conferences. Her research interest is Data Mining, Medical Image Analysis, Data Analytics, Evaluation of Algorithms, and E-Governance. She is presently working in Operations \& IT Department of IBS Hyderabad, IFHE University. 